\title{
The effect of reduced pressure on carbon dioxide flow boiling heat transfer in minichannels
}

\author{
Dariusz Mikielewicz ${ }^{1, *}$, and Blanka Jakubowska ${ }^{1}$ \\ ${ }^{1}$ Gdańsk University of Technology, Faculty of Mechanical Engineering, ul. Narutowicza 11/12, 80-233 Gdańsk, Poland
}

\begin{abstract}
In the paper presented are the results of the study on the effect of reduced pressure on flow boiling heat transfer data in minichannels as well as conventional ones. That effect renders that most of heat transfer correlations fail to return appropriate results of predictions. Mostly they have been developed for the reduced pressures from the range 0.1-0.3. The special correction has been postulated to the in-house model of flow boiling and condensation which modifies the two-phase flow multiplier as well as the temperature gradient in pool boiling. Four two-phase flow multiplier models were tested for this purpose, i.e. due to Friedel, Tran, Müller-Steinhagen and Heck and finally its in-house modification for applicability to minichannels. The model has been tested against a large selection of experimental data collected from various researchers to investigate the sensitivity of the in-house developed model. The collected experimental data came from various studies from literature and were conducted for the full range of quality variation and a wide range of mass velocity and saturation temperatures. In the work are presented the results of calculations obtained using the in-house developed semi empirical model on selected experimental flow boiling data related to carbon dioxide.
\end{abstract}

\section{Introduction}

Nowadays, there is an increasing interest in refrigerants featuring low Global Warming Potential (GWP). The reason of this concern can be attributed to the growing number of regulations and laws prohibiting the use of some of synthetic refrigerants. According to these regulations the new fluids used in e.g. air-conditioning and refrigeration applications cannot be manufactured with fluorinated greenhouse gases having GWP greater than 150 [1]. Within that document most of the substances used in refrigeration system have been regulated due to its Ozone Depletion Potential (ODP). Consequently one of the working fluids most extensively used in medium evaporation temperatures, such as for example R134a with GWP=1430 needs to be replaced by more environmentally friendly fluids. Previous studies have considered R152a [2] and the natural refrigerant $\mathrm{CO}_{2}$ [3] as possible replacements for R134a. However, $\mathrm{R} 152 \mathrm{a}$ is a flammable refrigerant and for the $\mathrm{CO}_{2}$ system, the working pressure is significantly higher than for R134a system. Apart from that drawback $\mathrm{CO}_{2}$, as compared to other contemporary fluids is a relatively safe one. It is non-toxic, non-flammable, non-explosive, inexpensive and can be coupled with most metals and plastics. Design of evaporators for use of the $\mathrm{CO}_{2}$ requires the exact determination of the heat transfer coefficient during flow boiling. Available in the literature empirical correlations give different results as compared to the results obtained experimentally. There is hardly any robust and recommended correlation for the purpose of calculation of carbon dioxide two-phase heat transfer, despite some devoted contributions [3]. There are many available experimental investigations into flow boiling heat transfer of all mentioned above working fluids in the literature. Unfortunately, the results published for some of these fluids are still inconsistent and difficult in mathematical modelling [4]. In the literature there are many empirical correlations for modelling of flow boiling heat transfer. As mentioned earlier, in case of $\mathrm{CO}_{2}$ most of well-known models does not exhibit a good consistency with experimental data. It was authors intention to show the performance of their own approach in predicting of flow boiling heat transfer coefficient on the example of the data collected from literature using the in-house developed model [5]-[8]. Based on the evidence of comparisons with experimental data two corrections incorporating the effect of reduced pressure have been postulated to the authors own model. The first one modifies the temperature gradient in flow boiling and is applicable only to that situation. The second correction relates to modification of the twophase flow multiplier and influences both the flow boiling or flow condensation. Presented model provides improved consistently of the predictions with the experimental data for the case of carbon dioxide data in a wide range of reduced pressures.

\section{The modelling}

The versatile semi-empirical model for calculations of flow boiling and flow condensation originally due to $\mathrm{J}$.

Corresponding author: Dariusz.Mikielewicz@.pg.edu.pl 
Mikielewicz [5] and the final version due to D. Mikielewicz et al. [6]-[8] has been tested for a significant number of experimental data and has returned satisfactory results for the case of the flow boiling process for numerous fluids. The fundamental hypothesis of the model is the fact that heat transfer during flow boiling with bubble generation can be modeled as a sum of two contributions constituting the total energy dissipation in the flow, namely the energy dissipation due to the shearing flow without the bubbles and dissipation resulting from the bubble generation. The final version of the model reads:

$$
\frac{\alpha_{T P B}}{\alpha_{L O}}=\sqrt{R_{M S}{ }^{n}+\frac{C}{1+P}\left(\frac{\alpha_{P b}}{\alpha_{L O}}\right)^{2}},
$$

In equation (1) $C=1$ for flow boiling and $C=0$ for flow condensation, Equation (1) also includes the empirical correction $P$ defined by equation (2). Occurring in the equation (1) the two-phase multiplier is raised to the power $n$ ( $n=0.76$ for turbulent, $n=2$ for laminar flow).

$$
P=2,53 \cdot 10^{-3} \cdot \mathrm{Re}^{1,17} \cdot B 0^{0,6} \cdot\left[\left(\phi_{L O}^{2}\right)_{M S}-1\right]^{-0,65},
$$

The two-phase flow multiplier present in eq. (1) has been recommended thus far as a Muller-Steinhagen and Heck [9] model or its in-house modifications (described in Table 1), but it must be stressed that any definition of the multiplier can be used for that modelling provided that it captures the convective flow boiling character properly.

In calculations presented below the sensitivity of the developed model to the selection of the two-phase flow multiplier has also been examined. For that purpose four models of two-phase flow multipliers were introduced into equation (1), namely modified correlation due to Friedel [10], Tran [11], Muller-Steinhagen and Heck [9], and the latter taking into account of the non-adiabatic effect [12]. Relationships, which describe the two-phase multiplier using during this analysis have been shown in Table 1.

Table 1. Two-phase multiplier models.

\begin{tabular}{cc}
\hline Autor(s) & Equation \\
\hline & $R_{M S}=\left[1+2\left(\frac{1}{f_{1}}-1\right) \cdot x \cdot\right.$ Con $^{m} \quad(3)$ \\
& $(1-x)^{1 / 3}+\frac{1}{f_{1 z}} x$ \\
Muller- & Turbulent flow \\
Steinhagen & $f_{l}=\left(\rho_{L} / \rho_{G}\right)\left(\mu_{L} / \mu_{G}\right)^{0.25}$, \\
and Heck & $f_{1 z}=\left(\mu_{G} / \mu_{L}\right)\left(\lambda_{L} / \lambda_{G}\right)^{1.5}\left(c_{p L} / c_{p G}\right)$ \\
L9] & $f_{l}=\left(\rho_{L} / \rho_{G}\right)\left(\mu_{L} / \mu_{G}\right) ; f_{l z}=\left(\lambda_{G} / \lambda_{L}\right)$ \\
& $m=0$ for conventional channels \\
& $m=-1$ for flow in minichannels \\
& Con $=\sqrt{\frac{\sigma}{g\left(\rho_{l}-\rho_{g}\right) \cdot d_{h}^{2}}}$ \\
\hline
\end{tabular}

$$
\begin{gathered}
\text { Friedel [10] } \begin{array}{c}
R_{F}=E+\frac{3.24 \cdot F \cdot H}{F r^{0.045} \cdot W e^{0.035}} \\
E=(1-x)^{2}+x^{2}\left(\frac{\rho_{l} f_{v}}{\rho_{v} f_{l}}\right) \\
F=x^{0.78}(1-x)^{0.2224} \\
H=\left(\frac{\rho_{l}}{\rho_{v}}\right)^{0.91}\left(\frac{\mu_{v}}{\mu_{l}}\right)^{0.19}\left(1-\frac{\mu_{v}}{\mu_{l}}\right)^{0.7} \\
\quad R_{T}=1+\left[4,3 \cdot \frac{(d p / d z)_{G O}}{(d p / d z)_{L O}}\right] \times \\
\left.N_{\text {conf }} \cdot x^{0,875} \cdot(1-x)^{0,875}+x^{1,75}\right] \\
N_{\text {conf }}=\sqrt{\frac{\sigma}{g\left(\rho_{l}-\rho_{g}\right) \cdot d_{h}^{2}}}
\end{array}
\end{gathered}
$$

$$
\begin{aligned}
& \begin{array}{l}
\text { Muller- } \\
\text { Steinhagen } \\
\begin{array}{l}
\text { and Heck } \\
\text { with non- } \\
\text { adiabatic } \\
\text { effects [12] }
\end{array}
\end{array} \quad R_{B}=\left\{\begin{array}{l}
R_{M S} \cdot\left(1-\frac{B}{2}\right) \quad \text { for } 0.1<x \leq 1 \\
R_{M S} \sqrt{1+\left(\frac{8 \cdot \alpha_{P b} \cdot d_{w}}{\lambda_{l} \cdot \operatorname{Re} \cdot \operatorname{Pr} \cdot \xi_{0} \cdot R_{M S}}\right)^{2}} \quad \text { for } 0 \leq x \leq C
\end{array}\right. \\
& B=\frac{2 \cdot q \cdot \frac{\rho_{l}}{\rho_{v}}}{f_{r} \cdot G(s-1) \cdot r}, \quad s=\sqrt[3]{\frac{\rho_{l}}{\rho_{v}}}
\end{aligned}
$$

Zhang and

Webb [13]

The model adopted for consideration may be used both for predicting heat transfer coefficients during boiling and condensation. It was expected that the accuracy of model predictions could be improved by some modifications to the empirical correction $P$, here by incorporation of the reduced pressure effect. Taking into account the reduced pressure in the empirical correction $\mathrm{P}$ in case of modeling the condensation process in the flow will not affect the obtained results of the calculations. This is due to the fact that the empirical correction $\mathrm{P}$, and thus the reduced pressure included in the calculations, are considered only in the part associated with the generation of bubbles, which is nonexistent when modeling the condensation process. The condensation process can only be influenced if the reduced pressure effect is applied to the model of twophase flow multiplier.

As mentioned above it was expected that the accuracy of model predictions could be improved by some modifications to the empirical correction $P$, here by incorporation of the reduced pressure effect. The modified in the present work empirical correction $P$ yields:

$$
P=\left(\frac{p_{\text {sat }}}{p_{k r}}\right)^{a} 2,53 \cdot 10^{-3} \operatorname{Re}^{1,17} B o^{0,6}\left[\left(\phi_{L O}^{2}\right)_{M S}-1\right]^{-0,65}
$$

The convective part of equation (1) can also be modified to include the effect of reduced pressure in the form: 


$$
R_{N}=R_{M S} \cdot\left[1-\left(\frac{P_{\text {sat }}}{P_{\text {crit }}}\right)^{a}\right]+1
$$

Therefore the general form of the model (1) with account of reduced pressure in the convection term and bubble generation term reads:

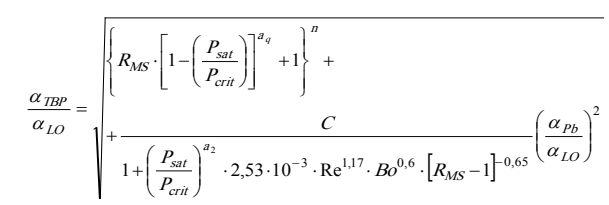

The exponents in eq. (9) have been derived using the multiple regression method and are equal to $a_{1}=1.61$ and $a_{2}=-1$.There is additionally another term in eq. (9) which should account for the fact that it may be prone to the reduced pressure. That is the pool boiling heat transfer coefficient. In the considered model the generalized Cooper model is used. That model is featuring the reduced pressure as one of the independent parameters. For that reason no amendments are required to that issue. The final form of the generalized dependence is described

$$
\alpha_{P b}=A \cdot q^{\frac{2}{3}} \cdot M^{-0,5} \cdot P_{r}^{0,12} \cdot\left(-\lg P_{r}\right)^{-0,55}
$$

The term A in the formula (11) is a constant dependent on the type of refrigerant and in the case of freons this value is 55 .

Specification of tested data is presented in Table 2. Some of the data fall into the range of minichannels, some of them to conventional ones. The value of the confinement number Con is used to distinguish between these data. Additionally in Table 2 presented are values of reduced pressure. Using the Kew and Cornwell [14] criterion, the available data bank was divided into

\begin{tabular}{|c|c|c|c|}
\hline Author(s) & Fluid & Con & $\overline{\boldsymbol{P}_{s a} / \boldsymbol{P}_{k}}$ \\
\hline $\begin{array}{c}\text { Docoloumbier et } \\
\text { al. [15] }\end{array}$ & & $\begin{array}{c}1.611 \\
- \\
1.412\end{array}$ & $\begin{array}{c}0.359- \\
0.472\end{array}$ \\
\hline Pamitran et al. [16] & & $\begin{array}{c}0.241 \\
- \\
0.483\end{array}$ & $\begin{array}{c}0.485- \\
0.61\end{array}$ \\
\hline $\begin{array}{l}\text { Mastrullo et al. } \\
\qquad[17]\end{array}$ & $\mathrm{CO}_{2}$ & $\begin{array}{c}0.113 \\
- \\
0.138\end{array}$ & $\begin{array}{c}0.382- \\
0.548\end{array}$ \\
\hline Yoon et al. [18] & & $\begin{array}{c}0.083 \\
- \\
0.099\end{array}$ & $\begin{array}{c}0.472- \\
0.61\end{array}$ \\
\hline
\end{tabular}
conventional size channels and minichannels.

\begin{tabular}{|c|c|c|}
\hline Choi et al. [19] & 0.415 & 0.61 \\
\hline Oh et al. [20] & $\begin{array}{c}0.071 \\
- \\
0.274\end{array}$ & $\begin{array}{l}0.413 \\
0.777\end{array}$ \\
\hline Dang et al. [21] & 0.274 & 0.69 \\
\hline Kim et al. [22] & $\begin{array}{l}0.096 \\
-0.16\end{array}$ & $\begin{array}{c}0.413- \\
0.777\end{array}$ \\
\hline Wu et al. [23] & $\begin{array}{r}0.526 \\
-0.78\end{array}$ & $\begin{array}{c}0.136- \\
0.472\end{array}$ \\
\hline Cho et al. [24] & $\begin{array}{c}0.048 \\
- \\
0.149\end{array}$ & $\begin{array}{c}0.472- \\
0.777\end{array}$ \\
\hline Zhao et al. [25] & 0.223 & 0.19 \\
\hline
\end{tabular}

Table 2. List of experimental data.

\section{Results}

It can be concluded that the transition from conventional size channels to minichannels takes place on average at channel diameter smaller than $1.5 \mathrm{~mm}$, i.e. Con $>0.5$. It should be also noted that the analysis of the parameters from Table 2, indicates the fact that collected for scrutiny experimental research covers a full range of quality and a relatively wide range of mass velocity.

In the first instance the attention will be drawn to the issue how the Muller-Steinhagen and Heck model is peforming at different reduced pressures in comparison to the Zhang and Webb model [25]. The latter has been especially developed to model pressure drop in minichannels and has a capability of differentiating between different values of reduced pressure. The comparison of the diagrams presented in Figures 1 shows that distributions of the pressure drop component for the same channel diameter are very similar for the case of the Zhang and Webb model and the model proposed here (9). Comparisons of the pressure drop determined with these two models at constant mass velocity $G$ and different channel diameters show some differences, but they are smaller than $20 \%$ between simulations.

In Fig. 2 presented are the results of predicting the twophase pressure drop in tubes using different models of two-phase flow multipliers. The data from Docoloumbier et al. [23] has been taken. Apparently, the model using formulation (9) performs best of other ones considered.

Belyaev et al. [25] tried to confirm the hypothesis that in case of high value of reduced pressure, the twophase flow structures in small diameter channels are similar to those occurring in conventional size diameter. Based on their study they observed that when reduced pressure is greater than 0.4 then is no differences between heat transfer during flow boiling in minichannels and conventional channels. Mauro [26] reports that at the same value of reduced pressure, the 
thermodynamic properties of refrigerants are very similar, wherein in case of transported properties, these properties are more divergent.

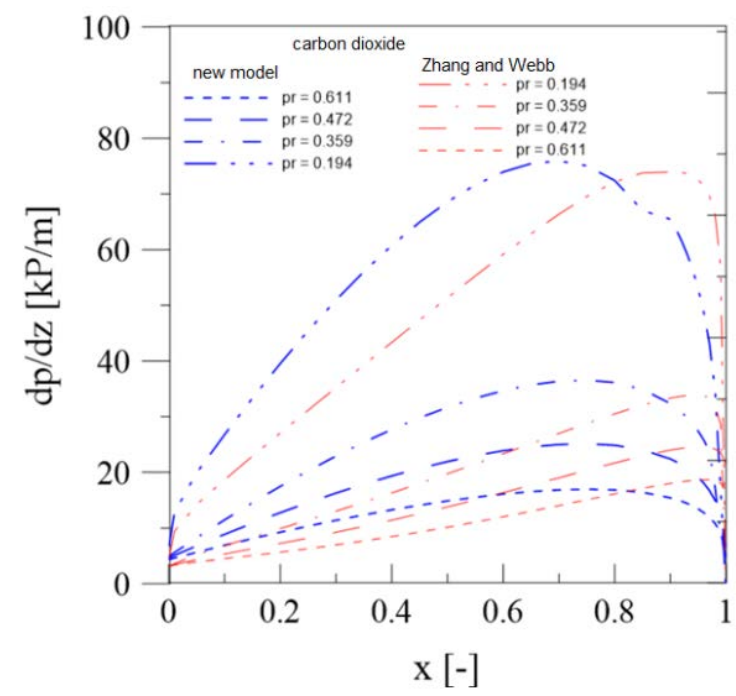

Fig. 1. Pressure drop distribution in function of quality for $\mathrm{CO}_{2}$ at different values of mass velocity; $\mathrm{G}=400 \mathrm{~kg} /\left(\mathrm{m}^{2} \mathrm{~s}\right)$, $T_{\text {sat }}=0^{\circ} \mathrm{C}, d=1 \mathrm{~mm}$, comparison of modified Muller-Steinhagen and Heck model (3) and Zhang and Webb.

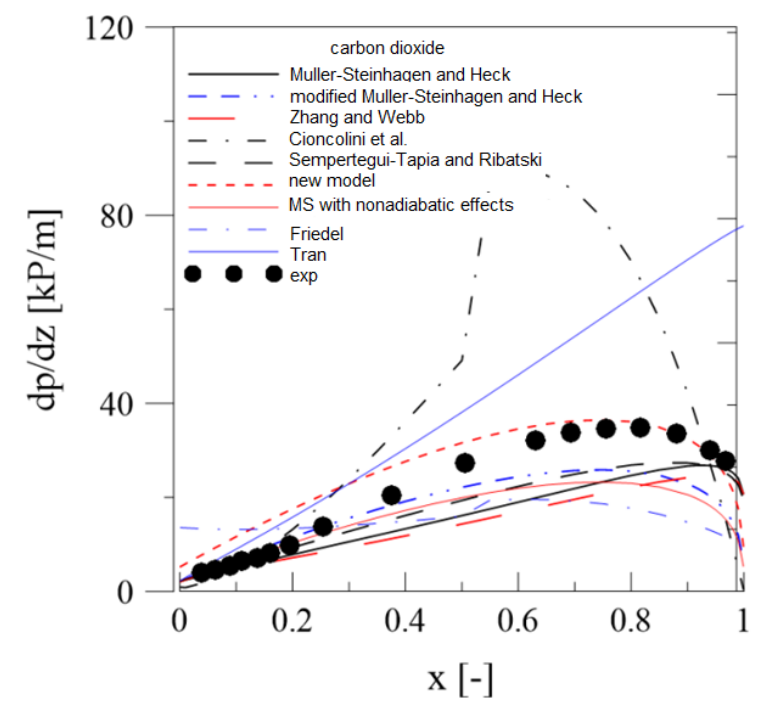

Fig. 2. Pressure drop distribution in function of quality for $\mathrm{CO}_{2}$ at different values of mass velocity; $\mathrm{G}=400 \mathrm{~kg} /\left(\mathrm{m}^{2} \mathrm{~s}\right)$, $T_{\text {sat }}=-10^{\circ} \mathrm{C}, d=1.42 \mathrm{~mm}$, comparison of different two-phase multiplier models [15].

In the following part, the basic model and its subsequent modifications, which have been selected for discussion, will be analyzed with respect to predictions of the heat transfer coefficient. Calculation are carried out using the model described by equation (5), where different twophase multiplier definitions have been assumed. The results of calculations are presented in Fig. 3.

In Figures 4-6 presented are the results of calculations of heat transfer coefficient using the model presented pressure drops related to boiling in flow using the relationships specified in Table 1. The presented calculations show that the models proposed by eq. (10) gave the very good match with the experimental data.

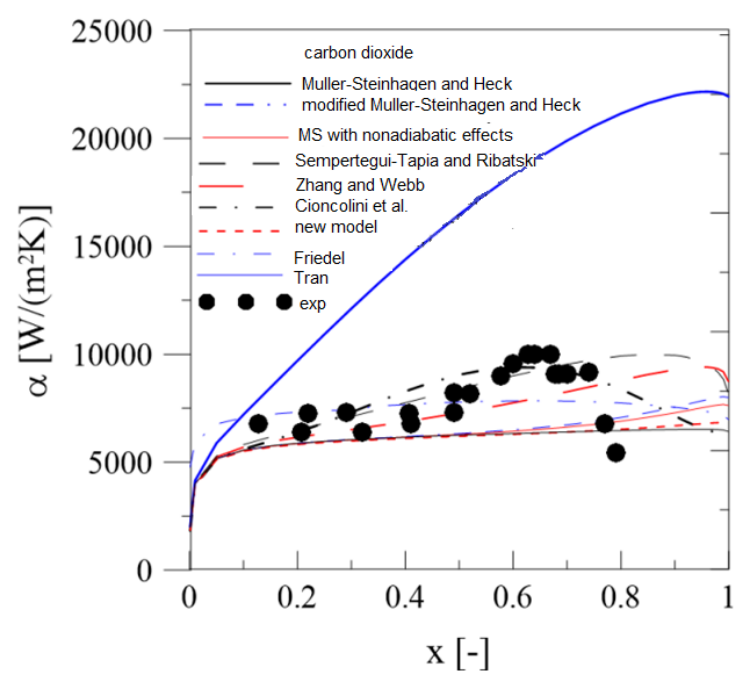

Fig. 3. Pressure drop distribution in function of quality for $\mathrm{CO}_{2}$ at different values of mass velocity; $d=0,53 \mathrm{~mm}, G=200$ $\mathrm{kg} / \mathrm{m}^{2} \mathrm{~s}, q=10 \mathrm{~kW} / \mathrm{m}^{2}, T_{\text {sat }}=0^{\circ} \mathrm{C}$, comparison of different twophase multiplier models [15].

The results of the analysis include all the collected experimental data specified in Table 2. According to the adopted systemization of channels, experimental data of Docoloumbier and al. [15] $\left(\mathrm{CO}_{2}\right), \mathrm{Wu}$ and others [23] $\left(\mathrm{CO}_{2}\right)$, Con $\geq 0.5$ was obtained while the remaining experimental database collected corresponds to the flow through a channel with conventional diameter. In performed calculations $\mathrm{MAE}=36.22 \%$.

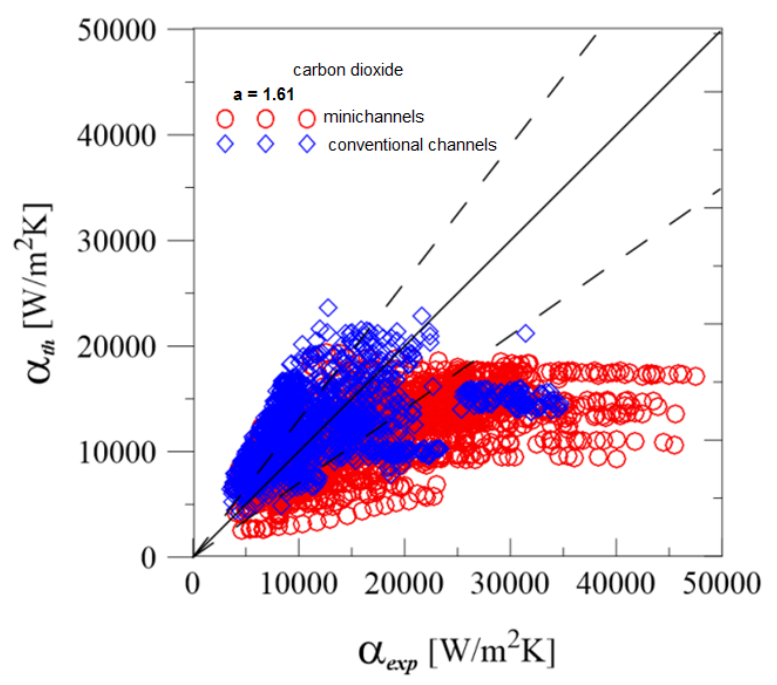

Fig. 4. Correllation of theoretical and empirical heat transfer data for $\mathrm{CO}_{2}$ at $\mathrm{a}=1.61$.

The graphs show that the correlation equations adopted for analysis reflect the experimental data in a satisfactory manner.

In addition, it should be added that to reduce the average relative error and increase the coefficient of determination in the linear regression model, the amount of experimental data falling within the error limits of \pm $30 \%$ in relation to the original form of the model adopted 
for analysis also increased. For the case of considered carbon dioxide data it amounts to $52 \%$. The histogram of deviations is presented in Fig. 6.

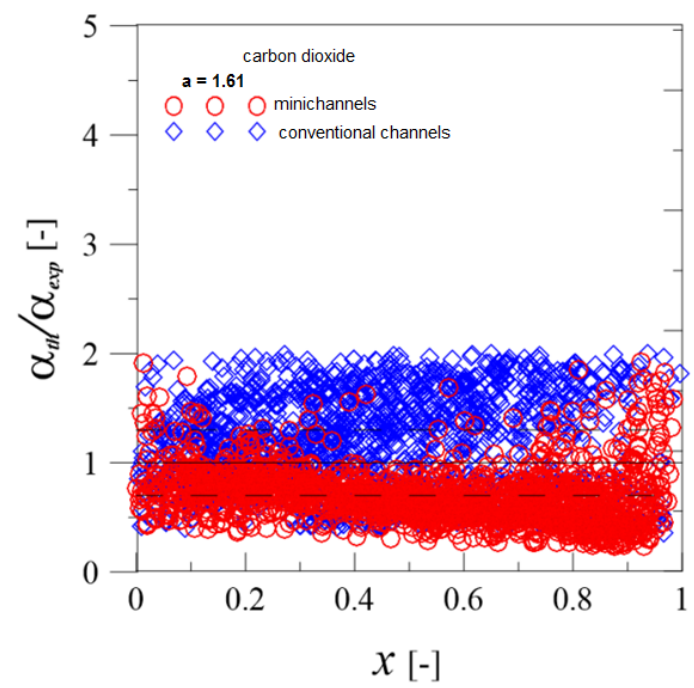

Fig. 5. Correllation of theoretical to empirical heat transfer ratio data in function of quality for $\mathrm{CO}_{2}$ at $\mathrm{a}=1.61$.

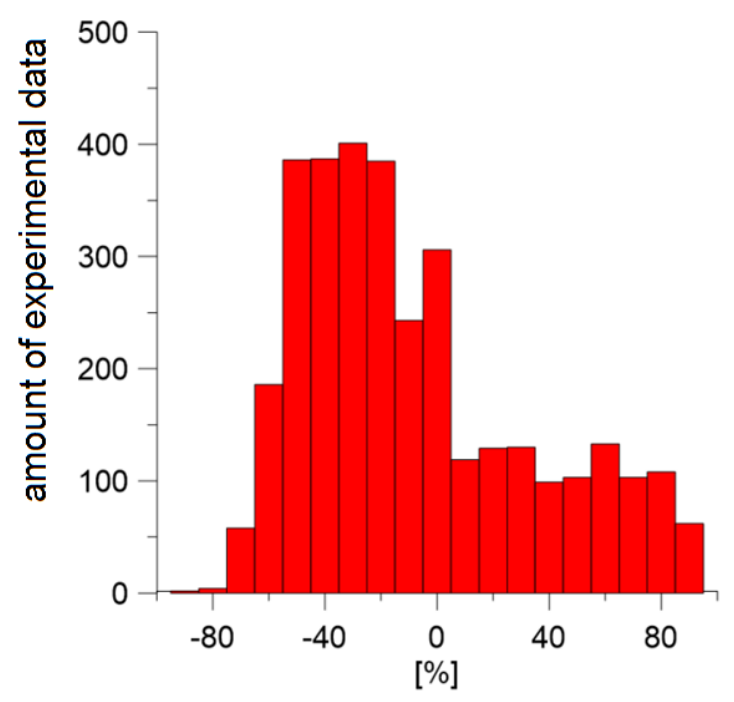

Fig. 6. Histogram of deviations of the calculateds results $\alpha_{t h}$.

\section{Conclusions}

The paper presents the analysis of the results of flow boiling calculations using an authors' own model to predict heat transfer coefficient in a wide range of reduced pressures for the case of carbon dioxide. The special correction has been postulated to the in-house model of flow boiling and condensation in which modified was the two-phase flow multiplier as well as the temperature gradient in pool boiling. Four two-phase flow multiplier models were tested for this purpose, i.e. due to Friedel, Tran, Müller-Steinhagen and Heck and finally its in-house modification for applicability to minichannels. The latter model has been tested against a large selection of experimental data collected from various researchers to investigate the sensitivity of the in-house developed model. The collected experimental data were conducted for the full range of quality variation and a wide range of mass velocity and saturation temperatures. The results show that change of the model which describes the two-phase multiplier is significant in case of $\mathrm{CO}_{2}$, where the best compliance with experimental data obtained using the Tran correlation. The results also show that taking into account appropriate two-phase multiplier model and reduced pressure effects can significantly contribute to the convergence with experimental data compared to original model. In authors' opinion, the proposed method to calculate the heat transfer coefficient is a reliable tool in engineering calculations e.g. designing heat exchangers [28-30].

Results presented in the paper have been carried out within the project 2017/25/B/ST8/00755 funded by the National Science Centre, Poland in years 2018-2021.

\section{References}

1. United Nations Environment Program (UNEP) Montreal Protocol on Substances that Deplete the Ozone Layer, 1997, (Final Act. United Nations, New York, USA).

2. M. Ghodbane, An investigation of R152a and hydrocarbon refrigerants in mobile air conditioning, Int. Proceedings of the international congress and exposition, pp. no. 1999-01-0874.

3. L. Cheng, G. Ribatski, and J. R. Thome, New prediction methods for CO2 evaporation inside tubes: Part II-An updated general flow boiling heat transfer model based on flow patterns, Int. J. Heat Mass Transf., vol. 51, no. 1-2, pp. 125-135, 2008.

4. D. Mikielewicz, B. Jakubowska, Prediction of flow boiling heat transfer coefficient for carbon dioxide in minichannels and conventional channels, Archives of Thermodynamic, vol. 37, no. 2, pp. 89106, 2016.

5. J. Mikielewicz, Semi-empirical method of determining the heat transfer coefficient for subcooled staurated boiling in a channel, Int. J. Heat Transfer, vol. 17, pp. 1129-1134, 1973.

6. D. Mikielewicz, J. Mikielewicz, and J. Tesmar, Improved semi-empirical method for determination of heat transfer coefficient in flow boiling in conventional and small diameter tubes, Int. J. Heat Mass Transfer, vol. 50, no. 19-20, pp. 3949-3956, 2007.

7. D. Mikielewicz and J. Mikielewicz, A Common Method for Calculation of Flow Boiling and Flow Condensation Heat Transfer Coefficients in Minichannels With Account of Nonadiabatic Effects, Heat Transfer Engineering, vol. 32, no. 13-14, pp. 1173-1181, 2011.

8. D. Mikielewicz, R. Andrzejczyk, B. Jakubowska, J. Mikielewicz, Analytical Model with Nonadiabatic Effects for Pressure Drop and Heat Transfer During Boiling and Condensation Flows in Conventional 
Channels and Minichannels, Heat Transfer Eng., vol. 37, no. 13-14, pp. 1158-1171, 2016.

9. H. Müller-Steinhagen, K. Heck, A simple friction pressure drop correlation for two-phase flow in pipes, Chem. Eng. Process, vol. 20, pp. 197-308, 1986.

10. L. Friedel, Improved friction pressure drop correlations for horizontal and vertical two-phase pipe flow, European Two-Phase Flow Group Meeting, 1979, p. Paper E2.

11. T. N. Tran, M. C. Chyu, M. W. Wambsganss, Twophase pressure drop of refrigerants during flow boiling in small channels: an experimental investigation and correlation development, Int. J. Refrigeration, vol. 26, pp. 1739-1754, 2000.

12. D. Mikielewicz, J. Wajs, R. Andrzejczyk, M. Klugmann, Pressure drop of HFE7000 and HFE7100 during flow condensation in minichannels. International Journal of Refrigeration, vol. 68, 226-241, 2016.

13. M. Zhang and R. L. Webb, Correlation of two-phase friction for refrigerants in small-diameter tubes, Exp. Thermal and Fluid Science, vol. 25, no. 3-4, pp. 131-139, 2001.

14. P. A. Kew, K. Cornwell, Correlations for the prediction of boiling heat transfer in small diameter channels, Appl. Therm. Eng., vol. 17, pp. 705-715, 1997.

15. M. Docoulombier, S. Colasson, B. J., P. Haberschill, Carbon dioxide flow boiling in a single microchannel - Part II: Heat transfer, Exp. Therm. Fluid Sci., vol. 35, pp. 597 - 611, 2011.

16. A. S. Pamitran, K.-I. Choi, J.-T. Oh, Nasruddin, Evaporation heat transfer coefficient in single circular small tubes for flow natural refrigerants of $\mathrm{C}_{3} \mathrm{H}_{8}, \mathrm{NH}_{3}$ and $\mathrm{CO}_{2}$, Int. Multiph. Flow, vol. 37, pp. 794-801, 2011.

17. R. Mastrullo, A. W. Mauro, A. Rosato, G. P. Vanoli, Carbon dioxide heat transfer coefficients and pressure drops during flow boiling: Assessment of predictive methods, Int. J. Refrig., vol. 33, no. 6, pp. 1068-1085, 2010.

18. S. H. Yoon, E. S. Cho, Y. W. Hwang, M. S. Kim, K. Min, Y. Kim, Characteristics of evaporative heat transfer and pressure drop of carbon dioxide correlation development, Int. J. Refrig., vol. 27, no. 2, pp. 111-119, 2004.
19. K.-I. Choi, A. S. Pamitran, C.-Y. Oh, J.-T. Oh, Boiling heat transfer of R22, R134a and $\mathrm{CO}_{2}$, Int. J. Refrig., vol. 30, no. 8, pp. 1336-1346, 2007.

20. H.-K. Oh, C. H. Son, Flow boiling heat transfer and pressure drop characteristics of $\mathrm{CO}_{2}$ in horizontal tube of $4.57 \mathrm{~mm}$ inner diameter, Appl. Therm. Eng., vol. 31, no. 2-3, pp. 163-172, 2011.

21. C. Dang, N. Haraguchi, E. Hihara, Flow boiling heat transfer of carbon dioxide inside a small-sized microfin tube, Int. J. Refrig., vol. 33, no. 4, pp. 655663, 2010.

22. Y. J. Kim, J. M. Cho, M. Kim, Experimental study on the evaporative heat trans-fer and pressure drop of $\mathrm{CO} 2$ flowing upward in vertical smooth and microfin tubes with diameter of $5 \mathrm{~mm}$, Int. J. Refrig., vol. 31, no. 5, pp. 771-779, 2008.

23. J. Wu, T. Koettig, C. Franke, D. Helmer, T. Eisel, F. Haug, J. Bremer, Investigation of heat transfer and pressure drop of CO2 two-phase flow in a horizontal mini-channel, Int. J. Heat Mass Transf., vol. 54, pp. 2154-2162, 2011.

24. J. M. Cho, M. S. Kim, Experimental studies on the evaporative heat transfer and pressure drop CO2 in smooth and micro-fin tubes of the diameters of 5 and $9.52 \mathrm{~mm}$, Int. J. Refrig., vol. 30, no. 6, pp. 986994, 2007.

25. X. Zhao, P. K. Bansal, Flow boiling heat transfer characteristic of $\mathrm{CO} 2$ at low temperatures, Int. J. Refrig., vol. 30, pp. 937-945, 2007.

26. A. V Belyaev, A. N. Varava, A. V Dedov, A. T. Komov, An experimental study of flow boiling in minichannels at high reduced pressure, Int. J. Heat Mass Transf., vol. 110, pp. 360-373, 2017.

27. A. W. Mauro, Flow boiling of refrigerants: from low to high reduced pressure, in UIT Summer School, 2017.

28. J. Wajs, D. Mikielewicz, Influence of metallic porous microlayer on pressure drop and heat transfer of stainless steel plate heat exchanger, Applied Thermal Engineering, 93, 1337-1346, 2016.

29. J. Wajs, D. Mikielewicz, E. Fornalik-Wajs, Thermal performance of a prototype plate heat exchanger with minichannels under boiling conditions, Journal of Physics Conference Series 745(2016), No. 032063. DOI:10.1088/1742-6596/745/3/032063

30. J. Wajs, D. Mikielewicz, B. Jakubowska, Performance of the domestic micro ORC equipped with the shell-and-tube condenser with minichannels, Energy, 157(2018) 853-861. 